\title{
Books beantiful books
}

TITLE:

Ethics and law in dental hygiene, 2nd edition

AUTHOR: P. L. Beemsterboer

PUBLISHER: Elsevier

PRICE: $\quad £ 25.99$

ISBN: $\quad 9781416062356$

\section{Ethics and Law in Dental Hygiene}

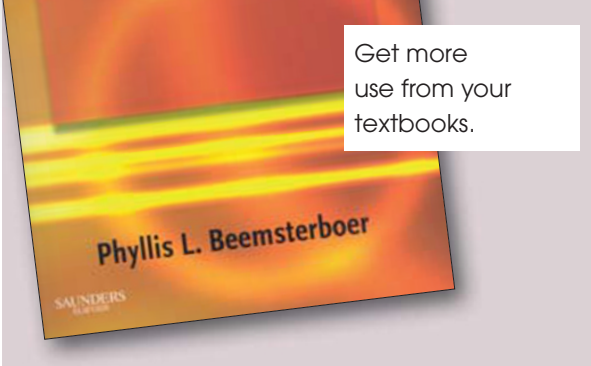

$\mathrm{T}$ his is one of those books that you know you should have on your shelf in the surgery but never get round to purchasing. We hear and read every week that someone, somewhere has brought a lawsuit against a dental professional for a variety of reasons. This book can help you understand the basics of where you could go wrong before you find yourself in such a situation.

Ethics and law in dental hygiene is written for dental hygienists - professionals who hold a unique place in the provision of oral health care. This book provides the most up-to-date ethics coverage for dental hygienists and experienced DCPs.

The information and guidance is suitable for entry-level dental hygiene students as well as experienced dental professionals looking to continue their professional development.

As with most law and ethics books our friends on the other side of the pond have a vast knowledge on this subject so you won't be surprised that this is aimed at our American hygiene colleagues. This is a book that will give you a clearly defined understanding of real world situations that we may encounter during our working life in general practice, community practice, or hospitals. As a hygienist we can relate to the majority of, if not to all, the 25 case studies that allow the hygienist to understand the types of ethical and legal dilemmas that may be encountered.

The book is divided into three sections: ethics, law and simulations and applications.

The first section presents the foundational aspects of ethics and introduces an ethical decision making tool for the analysis of ethical dilemmas.

The second section is devoted to the legal concepts and provides information on state practice acts and risk management.

'An excellent foundation and a valuable reference to guide you through this complex subject matter'

The third section provides 25 hypothetical case scenarios from various contributors with expertise in dental and dental hygiene ethics, ready for the reader to discuss and analyse. Questions to stimulate thought and discussion are provided and four small 'testlet' papers are also included which may help the student during their studies. A testlet is a short clinical scenario with a series of associated test questions that focus on critical thinking and problem-solving skills.

Finally, a listing of suggested activities and projects help expand upon the topics presented in this book and encourages additional thought and discussion.

Chapter key terms and a back-of-book glossary help ensure content mastery of the unique and often challenging language used within law and ethics.

If you can spend that little extra you can obtain this book with an electronic version of the textbook that allows students to search, highlight information, take notes, share notes and more. This total package makes it simple for students to make the most of their study time and get more use out of their textbooks!

Wherever you are in your dental hygiene career, Ethics and law in dental hygiene is an excellent foundation and a valuable reference to guide you through this complex subject matter with ease and understanding.

Gil Bagnall RDH

Marketing Manager, cpd4dentalnurses.co.uk
TITLE:

Basic guide to infection prevention and control in dentistry

AUTHOR: C. L. Pankhurst, W. A. Coulter

PUBLISHER: Wiley-Blackwell

PRICE:

$£ 19.99$

ISBN:

9781405176620

N

his is an excellent

book to introduce

new members of the team to a topic which will form the basis of their daily practice. It could be used as part of an induction programme or to update BOSIC Guide to
INFECTION
PREVENTION
AND CONTROL
IN DENTISTRY all team members. It is a legal obligation under the Health and Safety at Work Act 1974 for employers to ensure that all employees are proficient in the procedures necessary for working safely and ensuring that patients and visitors are not placed at any avoidable risk.

The book contains a comprehensive contents index so answers to specific queries can be found quickly and easily. It consists of 12 chapters which are colour coded along the binding of the book ensuring rapid navigation. Each chapter consists of block coloured titles dividing the information into small manageable portions of text. The use of coloured charts and diagrams is extensive throughout the book but I was particularly drawn to the photographs of surgery images which allowed me to relate topics directly to my own working environment.

The topics covered range from the essential basics such as working safely with sharps, hand hygiene and personal protection for prevention of cross infection to a thorough explanation on maintaining the dental unit waterlines and the rationale behind the importance of doing so. One of the final chapters explores the transport and postage of diagnostic specimens, impressions and equipment for servicing and repair which is essential reading as the United Nations Model Regulations for the Transport of Dangerous Goods is updated every two years.

A reference list and further reading list is included at the end of each chapter. The final chapter of the book is an appendix of tables which I found very useful and would recommend using them to form laminated wall charts to be used in each surgery. To summarise, this book is everything it promises to be: a basic guide to infection, prevention and control in dentistry.

\section{Sue Bagnall RDH Dip DHE}

Director, cpd4dentalnurses.co.uk 